\title{
Historia, antropología y arte: tres sujetos, dos pasados y una sola nación verdadera
}

\author{
por \\ Tomás Pérez Vejo ${ }^{1}$ \\ Escuela Nacional de Antropología e Historia-INAH \\ México
}

Análisis de la reordenación museística llevada a cabo por el Estado mexicano entre 1944, inauguración del refundado Museo Nacional de Historia, y 1964, inauguración de los museos nacionales de Antropología y del Virreinato, y del relato de nación que la sustenta.

Palabras Clave: México; siglo XX; nación; museos.

\section{EN EL LABERINTO DE LA INVENCIÓN DE LAS NACIONES}

El giro producido en los estudios sobre la nación en los inicios de la década de los ochenta del siglo pasado ${ }^{2}$ planteó un problema nuevo al que todavía hoy los historiadores seguimos dando vueltas. Si las naciones no eran, tal como había defendido el pensamiento político hasta las últimas décadas del siglo XX, realidades objetivas cuyo origen se perdía en la noche de los tiempos sino, tal como afirmaba el nuevo paradigma, construcciones imaginarias de carácter más o menos reciente, su «invención» se convertía en uno de los problemas

1 Este trabajo se inscribe en el proyecto de investigación «Museos, memoria y antropología: América y otros espacios de colonización», financiado por el Ministerio de Ciencia e Innovación del Gobierno de España (referencia: HAR2009-10107).

2 Entre 1983 y 1985 se publican las que podemos considerar las tres obras básicas en torno a las cuales se va articular un nuevo paradigma en torno al concepto de nación, Imagined Communities. Reflections on the Origin and Spread of Nationalism (Anderson, 1983), Nations and nationalism (Gellner, 1983) y Nationalism and the State (Breuilly, 1985). Para un resumen sobre estos cambios y sus características, véase Pérez Vejo, 1999. 
centrales de la historia de los dos últimos siglos. La invención de naciones como objeto de estudio. Algo que podía ser reconstruido, analizado y explicado en un tiempo histórico concreto y que consistiría, básicamente, en un proceso de socialización mediante el cual los individuos aceptan como propio el relato de una memoria colectiva que les dice lo que son y lo que no. El resultado de una coerción ideológica que desplaza memorias anteriores (locales, familiares, étnicas, etc.) en beneficio de una nueva de carácter nacional.

Este proceso de escritura de una memoria nacional puede seguir cauces y formas diversas. Para lo que aquí nos interesa, y sin mayores ambiciones de precisión conceptual, las naciones pueden proclamarse herederas de las organizaciones políticas que las precedieron, caso de la Europa atlántica donde, de manera general, se asumieron como prolongaciones de las grandes monarquías de la Edad Moderna; de organizaciones políticas desaparecidas, que se pretende resucitar, caso de algunos nacionalismos irredentos europeos, Cataluña, Escocia, etc.; o de naciones «naturales», definidas por la lengua, la raza o la cultura, sin existencia política previa, pero vivas en la memoria de sus habitantes, caso de muchos de los nacionalismos étnicos contemporáneos.

Se trata, obviamente, de tipos ideales, en el sentido weberiano del término, que en la práctica tienden a mezclarse y confundirse. Las naciones surgidas de las grandes monarquías europeas asumen como propia una historia previa al nacimiento de aquellas, a veces incluso con una cierta voluntad irredentista, y la existencia de una nación «natural» definida por la raza, la lengua o la cultu$\mathrm{ra}$; en las naciones irredentas, no solo la historia ocupa un lugar determinante sino también la reivindicación de una nación «natural» con una raza, una lengua o una cultura propias y diferenciadas; mientras que las naciones «naturales» buscan legitimarse a través de relecturas históricas del pasado que permitan afirmar la existencia de unidades políticas nacionales previas, piénsese en los delirios historicistas del primer nacionalismo vasco y sus batallas contra el reino de León o, más recientemente, en la Liga Norte italiana proclamándose heredera y continuadora de la Liga Lombarda altomedieval.

El objetivo último de los tres modelos es, sin embargo, el mismo. El fundamento de toda identidad colectiva es un relato de pertenencia que permite distinguir entre ellos y nosotros. Una narración coherente y cerrada que afirma la existencia de un sujeto colectivo, protagonista de la historia, al margen de los individuos que lo componen. El objetivo es el mismo pero no la forma de construcción del relato que varía de unos procesos a otros. En las naciones que se asumen como herederas de formaciones políticas previas tiende a articularse en torno a una alta cultura alfabetizada, gestada en torno a los círculos de la burocracia estatal, promovida a la categoría de cultura nacional; en las cons- 
truidas por oposición a las estructuras políticas existentes, por el contrario, la privilegiada es la cultura "popular», identificada como cultura nacional ${ }^{3}$.

Se podría decir que en el primer caso son la historia y los historiadores los que se convierten en parteros de la nación; mientras que en el segundo, etnólogos y/o antropólogos ocupan su lugar. A medio camino entre estos dos casos estaría el de aquellas naciones construidas en oposición a Estados existentes pero que reivindican la existencia previa de formaciones estatales que se quieren nacionales. Aquí la historia y la alta cultura estatal previa, asumida como propia aún en el caso de que no tenga nada que ver con la contemporánea, ocupan también un importante lugar en la definición de lo nacional. La historia, la antropología y la etnología como ejemplos paradigmáticos de la especial situación de las ciencias sociales entre la ciencia y la política o, si se prefiere, de la ciencia al servicio de la política ${ }^{4}$. Todas con un importante papel en la afirmación del Estado-nación y el proceso de modernización política promovida por este 5 .

En uno y otro relato los museos nacionales ocupan un lugar central. Lugares de memoria, no solo teatralizan y hacen visible un relato de identidad, en detrimento de otros relatos alternativos posibles, sino que le dotan de un aura de sacralidad que legitima su condición de verdadero. El museo como lugar en el que se expone lo que la nación es y lo que la hace diferente de otras comunidades nacionales, como «símbolo de identidad y [...] arca preciosa donde se guarda el patrimonio nacional» ${ }^{6}$.

\section{LOS DILEMAS DE LA CONSTRUCCIÓN NACIONAL EN MÉXICO}

En una primera aproximación, dentro del esquema conceptual al que se acaba de hacer referencia, el relato de nación mexicano podría considerarse

${ }^{3}$ Este sería el caso, por ejemplo, de los nacionalismos centroeuropeos, estudiados por Hroch, donde los recopiladores del folklore popular tuvieron un importante papel en el desarrollo de una identidad nacional. También el de los nacionalismos periféricos españoles, lo que explica fenómenos como la hegemonía de lo rural en la mitología nacional de sociedades tan predominantemente urbanas como Cataluña o el País Vasco. Para un análisis pormenorizado del desarrollo de este tipo de nacionalismos véase Hroch, 1985 (este autor habla en realidad del nacionalismo de las naciones pequeñas, el que él estudia, por oposición al de las naciones grandes, pero, en la práctica, el criterio de diferenciación que emplea es la carencia o no de Estado, no el tamaño; solo así se explica el que los daneses sean considerados, página 8, una «nación grande»).

4 Sobre esta peculiar situación de las ciencias sociales con respecto a la política, véase Weber, 1994.

5 Sobre estos aspectos, véase Foucault, 2006.

6 Florescano, 1997: 170. 
como una mezcla del segundo y tercer tipo. Una nación natural, que habría tenido su primera y temprana expresión en las organizaciones políticas previas a la llegada de los españoles, particularmente la azteca; que pierde su autonomía política a manos de una nación extranjera, España; y que la recupera gracias a una sangrienta guerra de la independencia ${ }^{7}$. Un relato de nación articulado como consecuencia en torno a la cultura popular y en contra de la cultura de las elites virreinales, que incluye, de manera más o menos armónica, el de una nación poscolonial construida e imaginada a partir de un proceso de descolonización política y económica, con la historia y la cultura virreinales convertidas en ajenas y extrañas al ser auténtico de la nación.

El proceso de construcción nacional mexicano, y como consecuencia su relato de nación, resulta sin embargo mucho más complejo de lo que esta primera aproximación puede dar a entender. Las elites que hicieron la independencia compartían con las peninsulares sangre, lengua y cultura ${ }^{8}$. Sus referentes difícilmente pudieron ser una raza, lengua y culturas populares, mayoritariamente indígenas, no solo ajenas sino, de manera general, despreciadas. Algo que se refleja de manera particularmente clara en la no reivindicación, habitual en los países colonizados, de una lengua propia diferente del castellano. Una reivindicación para la que, por cierto, en el caso mexicano, se daban una serie de circunstancias particularmente favorables. No solo en el momento de la proclamación de la independencia la mayoría de los habitantes no hablaban castellano sino que una de las lenguas nativas, el náhuatl, se encontraba en una situación privilegiada para haberse convertido en idioma de la nación. Ya lengua franca en amplios territorios antes de la llegada de los españoles, fue utilizada por los misioneros como lengua «general», lo que acrecentó su prestigio y la convirtió, durante la época virreinal, en una especie de idioma oficial de los naturales, «lengua general de los indios». Había sido además reivindicada como lengua culta por autores como Clavijero, quien afirma que en ella se podían explicar todos los conceptos del cristianismo y traducir cualquier pasaje de la Biblia sin necesidad de «mendigar vocablos de otras lenguas $»^{9}$. Sin embargo, a pesar de estas favorables condiciones, a las que hay que añadir que durante mucho tiempo se lo conoció como idioma «mexicano», ni siquiera en los momentos de mayor virulencia hispanófoba, varios e intensos a lo largo

7 Me estoy refiriendo, obviamente, a la forma como el Estado construyó e imaginó la nación, no a una realidad histórica en la que la nación no fue la causa de la guerra de independencia sino su consecuencia. Sobre este aspecto, véase Pérez Vejo, 2010b.

8 En realidad ni siquiera la llamada guerra de independencia fue un enfrentamiento entre criollos y peninsulares sino una guerra civil entre criollos. Véase Pérez Vejo, 2010b.

9 Clavijero, 1987: 239. 
del siglo XIX, se dio algo parecido no ya a la reivindicación del náhuatl como idioma oficial sino ni siquiera a la de un español mexicano diferenciado del peninsular. Lo máximo a que se llegó fue a la utilización del náhuatl, junto al castellano, como idioma de la nación en algunos actos cargados de especial emotividad histórico-nacional, por ejemplo, en la inauguración del monumento a Cuauhtémoc en 188710 .

Esta ausencia de dilema lingüístico refleja de manera particularmente clara la imposibilidad de las elites que hicieron la independencia de reivindicar una lengua distinta de la que hablaban y, en última instancia, una cultura nacional distinta de la que pertenecían, la misma que las del resto de las elites de la monarquía. Y es que en muchos aspectos hablar de las sociedades hispanoamericanas como sociedades poscoloniales tiene el mismo sentido, o la misma falta de sentido, que hacerlo en el caso de los Estados Unidos.

Lo que sí pudieron hacer las elites del nuevo Estado-nación, y lo van a hacer desde muy pronto, es reivindicar una alta cultura prehispánica como propia, ajenos a los indígenas vivos pero herederos simbólicos de los muertos. Una especie de apropiación simbólica del pasado que explica por qué en México prehispanismo e indigenismo no necesariamente son términos sinónimos sino incluso antitéticos. No es lo mismo reivindicar como propia una cultura ajena ya muerta, simple objeto de museo y de orgullo retrospectivo, que una viva que cuestiona los valores y formas de entender el mundo al que pertenecemos.

La presencia de estas dos altas culturas a las que remitirse y de las que considerarse herederos va a dar origen a dos relatos de nación alternativos e incompatibles. Uno, articulado en torno a la herencia española, para el que la nación mexicana nace con la conquista, se desarrolla durante los siglos virreinales y se emancipa con la independencia; otro, que lo hace en torno a la herencia prehispánica, para el que la nación mexicana, heredera y continuadora de las civilizaciones del altiplano, nada debía a la presencia española, nacida de las civilizaciones mesoamericanas, habría muerto con la conquista, sobrevivido a los oscuros siglos virreinales y resucitado con la independencia. La metáfora favorita del primero de estos dos relatos es la del hijo que, llegado a la edad adulta, deja la casa paterna y se independiza; la del segundo, un ciclo de nacimiento, muerte y resurrección ${ }^{11}$. Gravitando sobre ambos el debate sobre qué hacer con los indígenas contemporáneos ya que, paradójicamente, los dos son defendidos, de manera genérica y salvo excepciones puntuales, por una

10 Sobre los debates, o mejor falta de debates, en torno a la lengua en el México del siglo XIX, véase Pérez Vejo, 2010a.

11 Sobre la presencia y características de estos dos relatos de nación en el México del siglo XIX, véase Pérez Vejo, 2008. 
elite racial y racistamente blanca para la que el indio es el problema a resolver, objeto de la nación pero no sujeto de ella.

Estos dos relatos, en realidad dos proyectos de nación diferenciados y enfrentados, juegan de alguna manera el mismo papel que los nacionalismos oficiales y no oficiales a los que he hecho referencia más arriba, hasta el punto de que si para el primero es la historia como disciplina académica la que permite explicar el origen y las características de la nación mexicana, y no es casual que uno de los principales abanderados de este proyecto de nación, Lucas Alamán, sea a la vez uno de los historiadores más interesantes del siglo XIX mexicano; para el segundo es la antropología la que permitiría descubrir en los indígenas, presentes y sobre todo pasados, el alma auténtica de la nación purificada de las adherencias con las que los 300 años de dominio colonial la habían desfigurado y corrompido.

En este último proyecto la recuperación del alma indígena de México se convierte, necesariamente, en una de sus obsesiones más persistentes. De manera simétrica con el caso anterior tampoco es casual que uno de los liberales más influyentes del siglo XIX mexicano y uno de los representantes más conspicuos del segundo proyecto de nación ${ }^{12}$, Ignacio Ramírez «El Nigromante», en el contexto de una polémica con el político español Castelar, titule uno de sus artículos «La desespañolización», en el que propone como principal objetivo nacional acabar con cualquier vestigio de la herencia española. Nada demasiado novedoso si tenemos en cuenta que ya en 1869 había afirmado que en México «la sabiduría nacional debe levantarse sobre una base indígena».

El enfrentamiento entre ambos proyectos de nación será una constante de la vida mexicana posterior a la independencia, parece que en general con resultados siempre favorables al proyecto «prehispanista». Proyecto que, progresivamente, va adquiriendo una coloración más indigenista, culminada con el triunfo de la Revolución, que, si por un lado afirma el triunfo del indigenismo como política de Estado; por otro, encuentra en el mestizaje y el mito del mestizo el fundamento de la nacionalidad y de articulación del relato de la nación. Una forma simbólica de zanjar el viejo conflicto decimonónico, ni indios ni españoles sino mexicanos, el resultado de la mezcla de ambos.

12 La línea de fractura entre lo identitario y lo ideológico, aunque no exactamente coincidente, tiende a solaparse por lo que, de manera general, el primer discurso de nación es patrimonio de las derechas y el segundo de las izquierdas, el uso del plural es voluntario, y eso hasta nuestros días. Tal como afirma Brading «el pasado [...] contra el que todavía desata sus iras la elite intelectual, ya sea de persuasión liberal o socialista [...] es el de la Nueva España» (Brading, 1988: 210). 
Solución que, en sentido estricto, tampoco fue un hallazgo de la Revolución. Esta se limitó a oficializar, en su versión más indigenista, una retórica ya hegemónica durante el Porfiriato y que resume perfectamente la afirmación de Justo Sierra de que «los mexicanos somos los hijos de los dos pueblos y de las dos razas; nacimos de la conquista; nuestras raíces están en la tierra que habitaron los pueblos aborígenes y en el suelo español. Este hecho domina toda nuestra historia; a él debemos nuestra alma» ${ }^{13}$.

\section{El Museo Nacional de ANTRopología y el SER DE LA NACiÓn MEXICANA}

En este contexto de enfrentamiento entre dos proyectos alternativos de nación y el triunfo del segundo de ellos, primero con los liberales y después con la Revolución, el lugar de la antropología y del Museo Nacional de Antropología, el gran museo del régimen nacido de la Revolución, resulta extremadamente complejo. A diferencia de los museos antropológicos de los países coloniales europeos y de Estados Unidos, de manera general dedicados a los otros, los que no forman parte de la comunidad nacional ${ }^{14}$, y de los países no coloniales europeos en los que los museos antropológicos o etnológicos están dedicados al nosotros más primigenio y auténtico, el de México, como el de la mayoría de los latinoamericanos, está dedicado a unos otros que, dependiendo del relato de nación, son parte del nosotros nacional, y hasta el nosotros por antonomasia, pero sin que esto evite un ambiguo componente de «otredad». Una complejidad que se pone claramente de manifiesto si se analiza este museo no como un caso aislado sino como parte del programa de reordenación museística iniciado en 1939 con la creación del Instituto Nacional de Antropología e Historia, que tiene su primera plasmación con la inauguración del Museo Nacional de Historia en 1944 y que concluye veinte años más tarde, 1964, con la inauguración de otros dos museos nacionales más, el de Antropología y el del Virreinato.

El Estado mexicano nacido de la Revolución inicia con la creación del Instituto Nacional de Antropología e Historia ${ }^{15}$ un proceso de reorganización

13 Sierra, 1957: 117. La primera edición es de 1902.

14 Un caso particular es el del Museo de América de Madrid, dedicado tanto a los «otros», el mundo indígena americano, como a «nosotros», los españoles de América. Claro ejemplo de las ambivalencias del discurso nacional español sobre los territorios americanos de la Monarquía Católica.

15 Creado por Lázaro Cárdenas, decreto del 31 de diciembre de 1938, publicado en el Diario Oficial el 3 de febrero de 1939. El decreto incluía ya, artículo tercero, la fundación del primero de los tres grandes museos, el Nacional de Historia, de esta reorganización museística. 
museística ${ }^{16}$ cuyo objetivo fue representar el relato final y definitivo sobre el ser nacional de México. Relato condicionado por el triunfo de la antropología como ciencia del régimen ${ }^{17}$ y del indigenismo como ideología del Estado. La mejor expresión de este relato es el Museo Nacional de Antropología, «el museo» de México. Para su plena comprensión, sin embargo, es imprescindible tener en cuenta las complicadas relaciones, de discurso, que este mantiene con los otros dos museos nacionales creados en este mismo ciclo museístico, el Nacional de Historia y el Nacional del Virreinato. El primero, inaugurado en 1944, refundación del inaugurado por Porfirio Díaz en 1911, cuyo origen, lo mismo que el de Antropología ${ }^{18}$, se remontaba al Museo Nacional Mexicano creado por Guadalupe Victoria en 182519; el segundo, inaugurado, lo mismo que el de Antropología, en 1964. Un ciclo que se inicia con la separación del Museo Nacional de Historia del antiguo Museo de Arqueología, Historia y Etnografía, decisión debida en gran parte a Alfonso $\mathrm{Caso}^{20}$, uno de los grandes

16 Utilizo reorganización museística desde una perspectiva político-ideológica, no museológica, de discurso político y no de teoría sobre el museo, por lo que no necesariamente el periodo definido aquí coincide con las etapas establecidas por los estudios sobre la museología mexicana. Para una síntesis sobre la evolución de la museología mexicana, véase Morales, 2007.

17 Tal como afirma Annick Lempérière, la Revolución marcó el desplazamiento de la historia por la antropología como modelo de comprensión social y de memoria colectiva. Véase Lempérière, 1995.

18 Ambos nacen de la división de las colecciones del antiguo Museo Nacional de Arqueología, Etnografía e Historia.

19 Sus orígenes son incluso anteriores, en 1790, todavía en la época virreinal, se abrió al público el Gabinete de Historia Natural, origen del Conservatorio de Antigüedades creado por Iturbide en 1822 y base del Museo Nacional Mexicano de Guadalupe Victoria de 1825. La evolución posterior de este museo incluye la creación del Museo Público de Historia Natural, Arqueología e Historia por Maximiliano, 1864; recuperación de la denominación Museo Nacional con el triunfo de la República; y separación de las colecciones de historia natural de las de historia, arqueología y etnografía con la creación de dos nuevos museos en 1909, el Museo Nacional de Historia Natural y el Museo Nacional de Arqueología, Historia y Etnografía. Las colecciones del Departamento de Historia de este último museo serán la base del Museo Nacional de Historia, creado por el ya citado decreto de Lázaro Cárdenas de 1939 e inaugurado por el presidente Ávila Camacho el 27 de septiembre de 1944; las de los departamentos de Arqueología y Etnografía las del Museo Nacional de Antropología, inaugurado por el presidente López Mateos el 17 de septiembre de 1964. Véanse Fernández, 1987. Morales, 1994. Torre, 1982. Vázquez Olvera, 1997.

20 «Cuando se creó el Instituto Nacional de Antropología e Historia bajo la sabia y fuerte dirección de Alfonso Caso, él creía que había que dividir las dos etapas; se creó entonces el gran Museo Nacional de Antropología y le tocó al de Historia recoger toda la parte de la conquista en adelante», Silvio Zavala, director del Museo Nacional de Historia entre 1946 y 1954, entrevistado por Vázquez Olvera (Vázquez Olvera, 1997: 40). 
intelectuales orgánicos del régimen, y que se concluye con la creación de los nuevos museos nacionales de Antropología y del Virreinato.

El Estado nacido de la Revolución tenía por fin su relato fundacional, objetivo de todo régimen revolucionario, de lo que la nación era. Tal como escribió a propósito de las inauguraciones de 1964 Justino Fernández «por una o por otra razón la satisfacción de tal necesidad [la de dotar al país de museos] se había pospuesto [...] en vista de las realizaciones de 1964 puede decirse que por fin la Revolución Mexicana ha dado cima y ha hecho realidad ese importante aspecto de la cultura» ${ }^{21}$.

También relacionados con este ciclo estarían las inauguraciones, ese mismo año de 1964, del Museo de Arte Moderno en Chapultepec y del Museo de la Ciudad de México en el antiguo palacio de los condes de Santiago Calimaya. Ninguno de los dos incluye, sin embargo, la condición de nacional por lo que no son analizados aquí. Sí incluyen la denominación de nacionales los mucho más tardíos Museo Nacional de las Intervenciones (1981), Museo Nacional de Arte (1982) y Museo Nacional del Templo Mayor (1987) pero ya fuera de este ciclo museístico. Solo el caso del Museo Nacional de Arte (MUNAL), cuyos contenidos se solapan, en parte ${ }^{22}$, con dos de los tres museos que se están analizando aquí, el del Virreinato y el de Historia, exige un pequeño comentario. A diferencia de estos dos últimos no se ocupa de la historia ni de la antropología sino del arte, mexicano e internacional ${ }^{23}$. Extraña distinción, difícil de precisar, pero que muestra hasta qué punto su objeto cognoscitivo es otro. Se podría decir, de manera general, que es un museo de la alta cultura nacional, el arte sin adjetivos. Algo que tendría que ver con el primero de los tres modelos que se hablaba al principio de este artículo, un Estado-nación ya constituido que considera la alta cultura de las elites como fundamento de la cultura de la nación. La inclusión de algunas «obras de arte» del periodo virreinal plantea, sin embargo, algunos problemas interesantes sobre cómo el Estado-nación mexicano se asume también heredero de la alta cultura virreinal. No solo la visual, piénsese en el caso de Sor Juana Inés de la Cruz y su entronización como gloria literaria de México. Las conflictivas relaciones de este discurso del arte con el histórico-antropológico de los tres grandes museos inaugurados entre 1944 y 1964 quizás haría aconsejable incluir al MUNAL como elemento de comparación. Sin embargo, ni forma ya parte de este primer ciclo de reorganización museística del Estado posrevolucionario, por lo que su

21 Fernández, Justino, 1965: 3.

22 Incluye obras datadas desde el siglo XVI a mediados del siglo XX.

23 No depende, de hecho, como los anteriores del Instituto Nacional de Antropología e Historia (INAH) sino del Instituto Nacional de Bellas Artes (INBA). 
inclusión tendría algo de anacrónico, ni, en todo caso, aporta demasiado al problema de la inclusión/exclusión de lo virreinal en el relato de nación posrevolucionario tal como se expone en los casos del Museo Nacional del Virreinato y del Museo Nacional de Historia.

La fundación-refundación de los museos nacionales de Historia, Antropología y Virreinato refleja la voluntad del régimen político nacido de la Revolución de afirmar el discurso del mestizaje como política de Estado. El Museo Nacional de Antropología mostraría la raíz indígena, el Nacional del Virreinato, la española y el Nacional de Historia el México mestizo, fruto y consecuencia de los dos anteriores. La galería de la Revolución, anexa a este último, reafirmaría esa imagen escatológica, tan querida de todo régimen autoritario con veleidades totalitarias, de fin de la historia. La Revolución afirmaba su triunfo y el del mestizaje como la definitiva síntesis de lo que México era y representaba por los siglos de los siglos.

Lo primero que llama la atención en esta especie de Santísima Trinidad museística es la disimetría de las denominaciones. Dejando de lado, por el momento, el caso del Museo Nacional de Historia, que remite a un problema distinto, el Museo Nacional del Virreinato tiene un nombre que delimita su contenido temporal a un periodo histórico cerrado y concreto, el que corresponde a los tres siglos virreinales. El Museo Nacional de Antropología, por el contrario, se presenta, ya desde su denominación, como un museo intemporal, intemporalidad reafirmada por las imágenes con las que José Chávez Morado recubrió la columna monumental que da entrada a las salas, un relieve en bronce con alegorías del pasado, presente y futuro de México.

Resulta llamativo el que ninguno de estos dos museos, al margen del carácter inequívocamente histórico de los objetos que guardan, se presente como histórico, ya desde su denominación misma. El de Antropología de manera evidente, en él no se guardan, si hacemos caso a su denominación, objetos de un tiempo histórico determinado sino de cualquier época y cualquier periodo que tengan que ver con el ser del hombre mexicano. Una indefinición temporal que se explica porque su objetivo es, justamente, resguardar el pasado intemporal de la nación, valga el oxímoron, su alma, aquello que la hace ser lo que es y que está al margen del tiempo y de la historia, «la raigambre de nuestra personalidad histórica» ${ }^{24}$. El del Virreinato de manera menos obvia pero no por ello menos radical. Es ahistórico de manera diferente. Se exponen en él objetos que son parte de la historia de la nación pero de un tiempo cerrado y

24 «Discurso pronunciado por el señor profesor don José de Jesús Núñez y Domínguez, director del Museo Nacional de Historia en la ceremonia inaugural del mismo», reproducido en Vázquez Olvera, 1997: 27-34. 
concluido. No tanto parte de México como de un paréntesis en su devenir histórico «natural». Una especie de historia sin pasado ni futuro, carente como consecuencia de historicidad.

El Museo Nacional de Antropología se erige, apoyado por la impresionante calidad de sus colecciones, en el museo por excelencia de México, templo de la nación y, siguiendo la sugerente distinción de Benoît de l'Etoile, ejemplo paradigmático de un museo del «nosotros $»^{25}$ en el que la nación se reconoce y se identifica. Situado en uno de los laterales de la prolongación del paseo de la Reforma, el gran eje cívico en el que el Estado mexicano había escalonado desde el siglo XIX los grandes monumentos memorísticos de la historia nacional ${ }^{26}$, alberga dos colecciones en principio bastante dispares, tanto por el objeto de cada una de ellas como por la calidad de las piezas, pero a las que la exposición conjunta articula en un mismo discurso identitario de gran fuerza y coherencia mítica. En la planta baja se exponen muestras de las grandes civilizaciones prehispánicas, en general correspondería a lo que podríamos denominar Museo de Arte Antiguo Mexicano, Museo de Arqueología o, siguiendo la lógica del museo en el que se guarda el arte virreinal, Museo Nacional de las Civilizaciones Mesoamericanas. En la parte alta se ubican las colecciones de objetos etnográficos de los diferentes grupos indígenas del país.

La primera lectura es bastante obvia, el pasado prehispánico y el presente indígena se funden en una sola unidad y la suma de ambos es México. Es como si el Museo representase simbólicamente un mundo indígena contemporáneo que hundiera sus raíces en las civilizaciones prehispánicas anteriores a la conquista y de las que se erige en heredero y continuador. Por eso este museo, a diferencia de los demás museos nacionales, no se limita a un periodo histórico concreto. Los indígenas son una realidad intemporal. No se exhibe la historia de un tiempo definido sino un todo que se confunde con la nación. Esta sensación de intemporalidad se ve acentuada por el hecho de que las muestras etnológicas de la segunda planta parecen referirse a una especie de presente continuo, sin principio ni fin. No hay, de manera general, referencias cronológicas. Las representaciones de las distintas culturas indígenas pueden 2007.

25 Sobre la distinción entre «musées de Soi et les musées des Autres», véase L’Etoile,

26 Monumentos a Cristóbal Colón, Cuauhtémoc e Independencia. La monumentalización del paseo de la Reforma pasó por diferentes fases y proyectos, reflejo del complicado proceso de imaginación nacional mexicano, que incluyó los traslados de la estatua de Carlos IV, «el caballito», y el nunca concluido monumento a Isabel la Católica proyectado con motivo de las celebraciones del centenario. Sobre el contexto y significado político-ideológico de este último proyecto del Porfiriato, véase Pérez Vejo, 2010c. 
reflejar tanto formas de vida actuales como de un pasado histórico más o menos remoto. Son la expresión del ser inmutable de México.

El Museo Nacional del Virreinato, por el contrario, relegado a Tepotzotlán, en la periferia urbana de la ciudad de México, se refiere a un tiempo concluido y cerrado, el de una época virreinal que, aunque tiene que ver con México, no es México. Lejanía remarcada no solo por la ubicación del edificio sino también por las características de este, un antiguo convento jesuita, no menos impresionante desde el punto de vista arquitectónico que el edificio construido para albergar el Museo Nacional de Antropología, pero cuyo lenguaje arquitectónico remite también, lo mismo que sus colecciones, a un tiempo que ya no es el de México, queda incluso la duda de si en el discurso del Estado nacido de la Revolución alguna vez lo fue. Siguiendo la ya citada distinción de Benoît de l'Etoile sería más un museo del «otro» que de «nosotros».

Las diferencias entre ambos museos son claras ya en una primera aproximación. Una exacta comprensión de las mismas, sin embargo, exige ubicarlas en el contexto de los objetivos del Instituto Nacional de Antropología e Historia, del que ambos dependen, y de las relaciones de ambos con el Museo Nacional de Historia, la síntesis mestiza de la nación, quizás menos impresionante por lo que se refiere a sus colecciones pero cuya ubicación, en el antiguo Castillo de Chapultepec, y su carácter de museo de la historia de la nación lo dotan también de un alto contenido simbólico.

\section{MUSEOS Y NACIÓN EN EL DISCURSO DEL INSTITUTO NACIONAL DE ANTROPOLOGÍA E Historia}

El Instituto Nacional de Antropología e Historia tuvo, desde su constitución en 1939, el objetivo de realizar «Investigaciones científicas y artísticas que interesen a la Arqueología e Historia de México, antropológicas y etnográficas, principalmente de la población indígena del país» (Ley Orgánica del INAH, art. $2^{\circ}$, fracción III). Pero no una investigación fría y académica ya que el objetivo, tal como se precisa un poco más adelante, es «defender y proteger las muestras de arte de nuestros antepasados». Una especie de misión sacerdotal en la que la Escuela Nacional de Antropología e Historia cumpliría la función del seminario en el que se formarían los ministros de la nueva religión nacional y los museos dependientes del Instituto de lugares sagrados en los que serían expuestos de manera ordenada, comprensible y didáctica aquellos objetos que podían contribuir a la formación de un espíritu nacional y nacionalista.

Tal como afirmaba todavía en 1995 María Teresa Franco, en ese momento directora del Instituto, en el prólogo de la segunda edición del libro INAH una 
historia, publicado por el Instituto y que puede ser considerado como la historia oficial de la institución ${ }^{27}$, «No cabe duda de que la creación del Instituto Nacional de Antropología e Historia en 1939 fue un paso trascendental [...] en la formación de profesionales y en la promoción de los valores culturales en que se asienta la nacionalidad» ${ }^{28}$. Promoción de valores culturales nacionalistas en la que los museos ocupan, obviamente, lugar de privilegio.

Esta idea de los museos dependientes del INAH como fábrica de mexicanos nacionalistas nunca ha sido puesta en cuestión, ni siquiera en nuestros días. Todavía en 1988 Augusto Urteaga Castro-Pozo afirma, en la ya citada historia del Instituto, que:

Los museos del INAH han formado parte desde su origen de una política nacionalista [...] y han tenido como característica principal la preservación de bienes históricos y culturales considerados como representativos de la conciencia nacional. Durante todo el presente siglo, los museos se han constituido en una propuesta de la política cultural en la protección y conservación de lo nuestro ${ }^{29}$.

Es dentro de esta política nacionalista que el instituto crea los tres grandes museos a los que aquí se está haciendo referencia. El objetivo evidente parece ser el de una refundación del concepto de nación en el que lo mestizo, la mezcla de lo indígena y lo español, se convierta en la base identitaria de lo que significa ser mexicano. El asentamiento del régimen revolucionario y el fin de los grandes conflictos político-ideológicos de la primera época (cristeros, educación socialista...) había atenuado la virulencia del discurso indigenista de los primeros momentos, sustituido poco a poco por otro de carácter más integrador.

La voluntad política de mostrar el carácter mestizo de la nación mexicana es clara. Tal como afirmó en la inauguración del Museo Nacional de Antropología el Secretario de Educación Pública Jaime Torres Bodet ${ }^{30}$, disculpándose por haber hecho referencia a España en el día en que se honraban «tantas culturas decapitadas» (por los españoles, se entiende), «Sangre de España corre

27 «Es una memoria de la institución dedicada a sus propios trabajadores, y una obra de divulgación para el público interesado en conocer las actividades y servicios culturales que están a cargo del instituto» (Florescano, 1995: 15).

28 Franco, 1995: 17.

29 Urteaga Castro-Pozo, 1995: 295. La primera edición es de 1988.

30 La inauguración fue un acto especialmente solemne, presidida por el Presidente de la República, Adolfo López Mateos, contó con la participación de todos los miembros del gabinete, el cuerpo diplomático e invitados especiales de más de veinte países («Información general de las actividades del Instituto Nacional de Antropología e Historia durante el año 1964», 1964: 12). 
también por las venas de millones de mexicanos. Es fuerza en nosotros el mestizaje» ${ }^{31}$.

El Museo Nacional de Antropología mostraría la raíz indígena de México y el del Virreinato, la española, de manera que todo mexicano, al margen de cual fuese el color de su piel, su origen étnico o su identidad cultural quedaba convertido en mestizo. Se resolvía así un viejo conflicto, el de la necesidad de una nación homogénea, al que políticos y pensadores no habían dejado de dar vueltas desde el mismo momento de la independencia.

Y aquí se hace necesaria una pequeña digresión teórica. Mientras en las sociedades de Antiguo Régimen la homogeneidad resulta completamente irrelevante, en las nuevas sociedades nacionales se convierte en una necesidad ontológica ya que es la nación la que legitima el poder. Se podía ser súbdito de un monarca desde la heterogeneidad pero no miembro de una nación. Fue por eso que la vieja sociedad de castas colonial con sus exóticas e interminables divisiones de cambujo, morisco, albino, lobo, tente en el aire, torna atrás, no te entiendo ${ }^{32} \ldots$ dio paso en el siglo XIX a otra de ciudadanos iguales. Pero la afirmación jurídica de igualdad ante la ley no pudo evitar que las fracturas étnico-culturales siguieran siendo omnipresentes. Tal como afirmaba Francisco Pimentel en una fecha tan tardía como 1861:

En nuestro territorio viven tres razas, la blanca, la india y la mestiza. La raza blanca posee en alto grado la civilización europea, y es muy inteligente, pero desgraciadamente apática. La raza india se encuentra en un estado tal de envilecimiento, que no se puede contar con ella más que para trabajos puramente materiales. Los mestizos participan en parte de la civilización de los blancos, y al mismo tiempo son activos e inteligentes; pero se encuentran completamente desmoralizados, y ellos son los que cabalmente forman las bandas de ladrones y guerrilleros que aún traen revuelto al país («Junta de Colonización», 23 de agosto de 1865) ${ }^{33}$.

Una descripción que cuarenta años después de fundado el nuevo orden nacional se correspondía casi punto por punto con lo que había sido la estructura étnica de la vieja sociedad colonial, donde, en la práctica, las barrocas divisiones a las que he hecho referencia un poco más arriba se reducían a blancos, in-

31 «Información general de las actividades del Instituto Nacional de Antropología e Historia durante el año 1964», 1964: 7.

32 Estas clasificaciones corresponden a los distintos tipos de mestizajes entre blancos, indios y negros. «Cambujo», mezcla de «lobo» y «mestiza»; «albino», mezcla de «español»y «morisca»; «morisco», mezcla de «blanco» y «mulata»; «lobo», mezcla de «negro» e «india»; «tente en el aire», mezcla de «indio» y «loba»; «torna atrás», mezcla de «lobo» e «india»; «no te entiendo», mezcla de «cambujo» y «mulata»...

33 «Proposición presentada por Francisco Pimentel en la sesión de la Junta de Colonización el día 2 de agosto». 
dios y castas (mestizos). Pero todavía mucho más tarde, en los debates de la Asamblea Constituyente de 1917, se siguen utilizando prácticamente los mismos argumentos. Véase si no lo afirmado en la Comisión Dictaminadora por Paulino Machorro Narváez para quien lo que hacía débil a la nación mexicana era que «las diversas razas que vienen de la Conquista y que no acaban su fusión con los criollos, los mestizos, los europeos emigrados y los que han conservado la sangre pura antigua» ${ }^{34}$. Y nótese la reveladora forma de referirse a los indígenas «los que han conservado la sangre pura antigua». El fantasma de la pureza de originaria que parece rondar siempre a no importa qué discurso nacionalista.

Había, sin embargo, una diferencia fundamental, lo que no había sido un problema, la falta de homogeneidad, en la vieja sociedad virreinal lo era, y mucho, en la nueva sociedad nacional. La primera respuesta de las elites mexicanas fue el «blanqueamiento» de la población a través de la inmigración, el tiempo de los debates y polémicas sobre quiénes eran los inmigrantes que mejor se integraban en la «raza» nacional y cuáles las políticas inmigratorias más eficaces. Poco a poco, sin embargo, se fue abriendo paso la idea de que lo específicamente mexicano, el fundamento real de la nacionalidad, eran el mestizaje y el mestizo. Ya Clavijero había propugnado, hacia 1780, las ventajas de un mestizaje homogeneizador ${ }^{35}$. Habrá que esperar, sin embargo, hasta las décadas finales del siglo XIX para que autores como el citado Francisco Pimentel, Vicente Riva Palacio o Justo Sierra echen las bases de una corriente mestizofílica que alcanzaría su plena formulación en la influyente obra de Molina Enríquez, publicada en 1909, Los grandes problemas nacionales ${ }^{36}$. En la propuesta de Molina Enríquez el mestizaje dejaba de ser un problema, el mestizo se convertía en el auténtico representante de la nación y en el único capaz de neutralizar el carácter extranjerizante del criollo y la pasividad del indígena. Tesis que será retomada por la Revolución y convertida en política de Estado. Finalmente se había podido lograr, al menos en el nivel de lo imaginario, la homogeneidad tanto tiempo añorada: México se mostraba al mundo y a sí misma como una nación de mestizos en la que todos, al margen de sus rasgos étnico-culturales, eran el fruto de la mezcla entre indios y españoles. Es el tiempo del triunfo de la retórica del mestizaje como fundamento de la nacionalidad.

Como ya se ha indicado anteriormente, esta idea de mestizaje como fundamento de nacionalidad es preciso matizarla, al menos por lo que se refiere al discurso museístico posrevolucionario, y habría que ver si no en el discurso

\footnotetext{
34 Citado en Yankelevich, 2004: 110-111.

35 Clavijero, 1987: tomo II, 208 y ss.

36 Molina Enríquez, 1978.
} 
posrevolucionario tout court, ya que muestra una obvia disimetría entre uno y otro par, entre lo indígena y lo español, o si se prefiere entre la antropología y la historia. Mientras el Museo Nacional de Antropología, situado en el centro de la ciudad, transmite y recrea una idea de continuidad, no representa un periodo histórico de México sino a México; el Museo Nacional del Virreinato, ubicado en las afueras de la ciudad, transmite y recrea la idea de un periodo concluido y terminado. Esto permitía conjugar la mestizofilia revolucionaria con una no menos virulenta xenofobia, que en muchos casos es simple y llanamente hispanofobia. Por ejemplo entre los seguidores de Zapata, uno de cuyos elementos de movilización fue todavía el ¡mueran los gachupines! ${ }^{37}$; o en el Plan de Veladero de mayo de 1926, con base en la costas de Guerrero, en el que se proponía subsanar el «error» del plan de Iguala, despojando a los españoles de sus bienes y negocios. Una hispanofobia que adquirió tintes oficiales cuando uno de los diputados de la Asamblea Constituyente, Francisco Múgica, argumentó a favor de distinguir en la nueva constitución entre unos extranjeros y otros, pues no eran lo mismo los «perniciosos por excelencia, como los españoles y americanos» ${ }^{38}$ que los extranjeros en general. La aparente contradicción entre mestizofilia e hispanofobia se resolvió convirtiendo la aportación española al mestizaje y a la construcción de la nacionalidad mexicana en algo terminado y concluido. Un tiempo histórico pasado y, en última instancia, superficial. No así la indígena, la raíz que seguía aportando su savia a la nacionalidad mexicana y que constituía su sustrato profundo y verdadero. En palabras de Leopoldo Zea, describiendo a los campesinos de la Revolución:

No sabían sino lo que sus padres y los padres de sus padres les habían enseñado en una cadena que se remontaba hasta un pasado que iba más allá de la época en que unos hombres blancos les habían arrancado sus tierras, les habían humillado y sometido; pero no habían podido borrar de sus mentes los viejos ritos y el sentido de una vida en la que lo traído por los blancos era solo superficial ${ }^{39}$.

Tan superficial, habría que precisar, como la lengua o la religión. Pero no se trata de polemizar con Zea sino de mostrar cómo la idea de que la raíz española formaba parte de la historia que pasa y la indígena de la antropología que permanece fue parte consustancial del imaginario de las elites políticas e intelectuales mexicanas de mediados del siglo pasado.

37 Para la hispanofobia como elemento de movilización social en la zona cañera del Estado de Morelos durante la Revolución, véase Womack, 1969: 30-31. Sobre la hispanofobia revolucionaria, en general, Knight, 1974; e Illades, 1991.

38 Citado por Yankelevich, 2004: 109.

39 Zea, 1953: 69. 
Para mostrar esta oposición entre la historia, superficial y efímera, y la antropología, profunda y eterna, se hace, en el discurso museístico de 1964, una definición de lo antropológico claramente sesgada. No se entiende muy bien por qué el llamado calendario azteca es una pieza antropológica y no lo son los retablos barrocos que se guardan en Tepozotlán. Lo que está detrás no es solo la hispanofobia de la Revolución, que también, sino, sobre todo, esa idea de una nación basada en la alta cultura de las civilizaciones prehispánicas y la cultura popular del modelo al que se ha hecho referencia más arriba. El mestizaje no podía ser equitativo. No se podía poner en un mismo plano a lo español, extranjero y ajeno al ser verdadero de la nación, con lo indígena, representación de lo más íntimo y auténtico de la nacionalidad mexicana. La nación era lo popular y lo popular, en México, es lo indígena.

A diferencia del Museo Nacional del Virreinato, el de Antropología es la representación intemporal del hombre mexicano. Lo indígena y el pasado indígena se convierten en la materia prima con el que aquel se construye. Por eso la continuidad entre el pasado prehispánico y el indígena contemporáneo. Se representan juntos porque son lo mismo. Continuidad entre el mundo prehispánico y el México contemporáneo que es puesto explícitamente de manifiesto por el Secretario de Educación Pública Jaime Torres Bodet, en el ya citado discurso de inauguración, con su afirmación de que:

No sugerimos [...] un regreso utópico a la Liga de Mayapán, a la teogonía teotihuacana, a los métodos bélicos de Axayáctl o a las normas suntuarias de Moctezuma. Sin embargo, nuestra visión general de México resultaría arbitraria y falsa si no admitiéramos francamente que el cielo que contemplamos, las montañas que nos custodian y la tierra que nos sustenta fueron el marco de una evolución secular, de cuyos trofeos debemos reconocernos depositarios respetuosos y agradecidos ${ }^{40}$.

Es decir, por un lado se asume la otredad de las culturas mesoamericanas pero por otro se las proclama parte de un pasado que es nuestro y del que somos depositarios «respetuosos y agradecidos». Pocos ejemplos más claros de ese nacionalismo orgánico para el que la nación es una comunidad de vivos y muertos, tan importantes los segundos como los primeros. Los muertos de los que descendemos y frente a los que somos responsables. No sugerimos un regreso a la teogonía teotihuacana, pero, emotivamente, ella es más nuestra incluso que las teogonías en las que creemos. Algo que unos pocos años más tarde, en 1979, precisará todavía de manera mucho más clara Ignacio Bernal, director del INAH de 1968 a 1971, «Para el extranjero [...] la Arqueología de

40 «Información general de las actividades del Instituto Nacional de Antropología e Historia durante el año 1964», 1964: 12. 
México resulta un trabajo académico [...] Para el mexicano es parte de su pasado y, por tanto, de su propia vida ${ }^{41}$. Afirmación que deja meridianamente claro tanto el papel de la arqueología como del mundo prehispánico en el relato de nación de México.

Sin embargo, en todo este discurso hay algo que chirría. Este indigenismo retórico no puede ocultar la realidad de una sociedad donde, igual antes que después de la Revolución, el mismo indígena convertido en sujeto de nacionalidad vive una situación de marginación cotidiana y donde el racismo más rampante impregna una gran parte de la cultura popular. Incluso, desde una perspectiva propiamente antropológica, la realidad de un indigenismo que desde sus orígenes, por ejemplo en la obra de Manuel Gamio ${ }^{42}$, afirma la idea de unos indígenas que no son mexicanos y a los que es necesario hacer mexicanos si México quiere ser un país moderno.

Este sería, según el antropólogo mexicano Eduardo Nivón, el «origen de la antropología mexicana y su gran cruz» ${ }^{43}$. Cruz que esconde una especie de contradicción imposible, por un lado, se propugna integrar a los indígenas en la vida nacional, hacerlos mexicanos, pero por otro se propone, también como objetivo prioritario, proteger su mundo material y moral de aquellas influencias que puedan contaminarlo. Son, a la vez, sujeto de los desvelos de la antropología por mejorar sus condiciones de vida y reliquias de un pasado que se debe de conservar ya que representan la esencia de la nación, su pureza originaria.

Lo sorprendente del Museo Nacional de Antropología es su capacidad para articular esa realidad social profundamente racista con la exaltación del pasado y presente indígenas. Tal como está concebido reafirma la idea de que lo indígena y lo blanco son, a pesar de la retórica del mestizaje, realidades distintas. El mundo de los indígenas se muestra como algo inmutable al margen del tiempo, es el territorio de la antropología, de lo que permanece; el mundo de los blancos, por el contrario, cambiante y dinámico, es patrimonio de la historia, del tiempo que pasa, por eso no tiene cabida en este museo sino en el Nacional de Historia, al otro lado del paseo de la Reforma.

Paradójicamente, sin embargo, el Museo Nacional de Antropología incluye, en las salas dedicadas a la gloria del pasado prehispánico, un discurso histórico que permite visualizar, por un lado, el desarrollo de las grandes civilizaciones mesoamericanas, desde el poblamiento de América hasta los mexicas; por otro, la hegemonía de las culturas del altiplano como raíz de la nacionalidad, con la sala mexica convertida en el santa sanctorum del museo, no solo

\footnotetext{
41 Bernal, 1979: 9.

42 Gamio, 1982, la primera edición es de 1916.

43 Citado en Palacios Ramírez, 2004: 143.
} 
por la calidad de las piezas expuestas sino por su ubicación ${ }^{44}$, centralidad de lo mexica percibida, y aplaudida, ya por los contemporáneos, «en sus amplias crujías [las del Museo Nacional de Antropología] se organizaron los salones dedicados a las diversas culturas del antiguo mundo indígena de México y entre ellas tiene lugar central e importancia capital la Sala Mexica, en donde quedaron [...] instaladas las grades esculturas aztecas» ${ }^{45}$. Un pasado indígena que sí que tiene historia y cuya relación con el mundo indígena del primer piso del museo, carente de ella, resulta extremadamente ambigua.

En una primera lectura habría una clara relación entre el pasado prehispánico y los indígenas contemporáneos, con aquel como la raíz de éstos. Sin embargo, a pesar de exponerse en el mismo edificio y como parte del mismo museo, las colecciones etnográficas carecen por completo de historicidad. Las culturas indígenas contemporáneas son representadas como fósiles vivientes, al margen del tiempo. Tan fósiles que son esterilizados para su representación. Ningún objeto industrial, por ejemplo, presente en la vida cotidiana de cualquiera de las comunidades indígenas de México tiene cabida en el Museo Nacional de Antropología. Seres puros e incontaminados sobre los que los cinco siglos de contacto con la civilización occidental no han dejado ninguna huella. Fueron, son y seguirán siendo así. Representan la nación pero no son la nación. La nación real, la que vive, no es, a pesar del mito fundacional, la de los indígenas, es la de los blancos o la de los mestizos. Y en este sentido, paradójicamente, el Museo Nacional de Antropología es, a la vez, un museo del «nosotros», el pasado prehispánico asumido como pasado de la nación, y un museo de la otredad, el mundo indígena al margen de la historia.

Hay una historia blanca y mestiza pero no una historia indígena, el pasado prehispánico forma parte de la historia de México, no de la de los indígenas; lo mismo que hay una antropología indígena pero no una antropología blanca o mestiza. No hay representaciones de grupos étnicos no indígenas en la segunda planta del Museo Nacional de Antropología, ni negros, ni españoles, ni mestizos, por no hablar de las diferentes colonias extranjeras establecidas en el país desde el momento de la independencia y que desarrollaron modelos culturales propios, de los libaneses a los chinos, tienen cabida en él. Simétricamente no hay una sección prehispánica en el Museo Nacional de Historia. La historia de México, según el discurso de este último museo, comienza con la conquista, con la llegada de los españoles, en él «se asistirá visualmente al de-

44 La planta principal del Museo Nacional de Antropología recuerda de manera bastante precisa la de un templo cristiano, con la sala mexica situada en el centro de un imaginario ábside.

45 Fernández, 1965: 3. 
sarrollo de nuestro ser nacional a partir de 1521 hasta nuestros días» ${ }^{46}$; la antropología del hombre mexicano, por contrario, no comienza, es indígena e inmutable. Una especie de vestal, como todas las vestales estéril y consagrada a dios, al dios de la nación en este caso.

Tan inmutable que no solo se supone que por ella no ha pasado la historia, lo indígena en el imaginario mexicano remite siempre a lo prehispánico, sino que el objetivo de las instituciones políticas y académicas sería la conservación de su pureza originaria. Un imaginario subyacente que explicaría por qué el proyecto de dedicar tres grandes museos a cada uno de los grandes periodos de la historia de la nación, el Museo Nacional de Antropología a la época prehispánica, el Nacional de Virreinato a la colonial, y el Nacional de Historia al México independiente, acabó convertido en un museo de antropología, en el que se guarda la esencia de lo mexicano; uno de no se sabe qué, en el que se guardan los vestigios de un tiempo raro, parte de México pero que no es México; y otro de historia, en el que, a diferencia de los anteriores, el protagonista es el tiempo, el cambio histórico que afecta únicamente a blancos y a mestizos.

Este último museo, el Nacional de Historia, plantea, en el conjunto del discurso museístico del Estado nacido de la Revolución, algunas cuestiones y problemas de indudable relevancia. Ubicado en un lugar especialmente simbólico, el castillo de Chapultepec, podría considerarse, por el tipo de objetos que guarda (armas, relojes, indumentaria, muebles, cerámica, joyas, etc.) al menos tan antropológico y etnográfico como el que se encuentra a sus pies, al otro lado del paseo de la Reforma; y por la riqueza de sus fondos virreinales al menos tan del virreinato como el del convento de Tepozotlán. La diferencia consiste en que, al contrario de los dos anteriores, tiene una clara voluntad de mostrar el cambio, la historia, desde su denominación hasta la forma como son expuestas sus colecciones.

La planta baja se organiza a partir de un orden cronológico estricto, «Conquista», «Misioneros», «Armas coloniales», «Virreinato», «Guerra de Independencia», «Imperio de Iturbide», «La República», «Intervención Americana», «La Reforma y el Segundo Imperio», «Época Porfiriana» y «La Revolución ${ }^{47}$. El argumentos es la sucesión de épocas históricas, mostrada no solo a través de las piezas que se exponen sino mediante las pinturas murales que de-

46 «Discurso pronunciado por el señor profesor don José de Jesús Núñez y Domínguez, director del Museo Nacional de Historia en la ceremonia inaugural del mismo», reproducido en Vázquez Olvera, 1997: 27-34.

47 «Toda la planta baja estaba concebida como un paso por la cronología de la historia de México», Silvio Zavala, director del Museo Nacional de Historia entre 1946 y 1954, entrevistado por Vázquez Olvera (Vázquez Olvera, 1997: 40). 
coran sus paredes, y la enumeración de sus títulos hace innecesario cualquier comentario al respecto: El Retablo de Independencia de Juan O'Gorman había sido encargado a Rivera pero murió antes de poder realizarlo; La Reforma y la caída del Imperio de Orozco; y Del porfirismo a la revolución de David Alfaro Siqueiros ${ }^{48}$.

Ni el tiempo ahistórico del Museo Nacional de Antropología ni el cerrado y concluido del virreinal sino el que pasa, cambia y se transforma, el de la historia. Los mismos objetos y pinturas que en el Museo Nacional del Virreinato son parte de una otredad más o menos difusa, en el Museo Nacional de Historia se convierten en parte fundamental del «nosotros» que nos hace ser lo que somos. La historia empieza con la conquista y es la de los blancos, no la de los indígenas. Nada raro si consideramos que en la retórica mestizofílica revolucionaria los indígenas siguen siendo más objeto que sujeto, la masa de la que está hecha la nación pero no quién la hace, en afortunada expresión de Johanna Lozoya solo «las manos indígenas de la raza española» ${ }^{4}$.

\section{CONCLUSIÓN}

La reordenación museística posrevolucionaria del periodo 1944-1964 permite sacar algunas conclusiones sobre la refundación de la nación llevada a cabo por la Revolución, sobre el lugar de la historia y antropología en el discurso político mexicano y sobre el complejo papel del indigenismo como ideología de Estado.

La antropología mexicana nacida de la Revolución retoma como eje de sus reflexiones teóricas y prácticas una de las grandes obsesiones que habían atravesado el discurso político-intelectual de la nación a lo largo del siglo XIX y que no es otro que el problema del indio, qué hacer con una población indígena mayoritaria cuyo nivel de atraso y características raciales se convertían, en la visión decimonónica, en una rémora para el avance del país. Qué hacer cuando además el discurso ideológico del nacionalismo mexicano había apostado desde muy pronto por la imagen de una nación mexicana hija, heredera y continuadora del pasado prehispánico. Ya en el mismo momento de las luchas de independencia un autor como Carlos María de Bustamante pudo afirmar «Manes de Moctezuma estáis vengados». La respuesta del siglo XIX fue de una cierta habilidad retórica. Estableció una especie de separación tácita entre los indígenas del pasado y los, en expresión de la época, degenerados indígeZavala.

48 Los temas fueron propuestos por el segundo director del museo, el historiador Silvio

49 Lozoya, Johanna, 2010. 
nas contemporáneos. Una especie de expropiación simbólica mediante la cual el pasado indígena se convertía en pasado de la nación.

Con el triunfo de la Revolución, el indigenismo tomó nuevos bríos y pasó a convertirse en una suerte de política de Estado. La preocupación de los problemas de México llevó nuevamente al problema de lo indígena en la configuración de la nación. Mientras en el siglo XIX, unos y otros, liberales y conservadores, convencidos de la inferioridad étnica de los grupos indígenas, apostaron sin apenas matices por un blanqueamiento de la población, el modelo era Estados Unidos y sus políticas migratorias; la Revolución, que tuvo un marcado carácter xenófobo, apostó por la idea del mestizaje como fundamento de la identidad nacional, desde la mestizofilia de Molina Enríquez a los delirios sobre la raza cósmica de Vasconcelos. Los mestizos fueron convertidos en la etnia mítica sobre la que se fundaba la nación, un proceso que se había iniciado en el último cuarto del siglo XIX con la publicación de México a través de los siglos, pero que con la Revolución cobraba plenamente carta de naturaleza. Esta nueva imagen de la nación tuvo como resultado inmediato la reivindicación de lo indígena como parte de la nación, algo que retóricamente se había mantenido ya desde el mismo momento de la independencia pero que ahora introduce un matiz importante. No son solo los indígenas históricos sino también los indígenas contemporáneos los que representan la nación. Son el origen de México y la expresión de su alma más íntima y auténtica. Un fenómeno que está, sin duda, detrás del florecimiento de la antropología mexicana durante toda la primera mitad del siglo XX. Una antropología al servicio del Estado, confundida con el indigenismo y cuya función político-ideológica explica su situación de privilegio en el entramado académico-institucional del régimen nacido de la Revolución (Instituto Nacional Indigenista, Instituto Nacional de Antropología e Historia, Escuela Nacional de Antropología e Historia y Museo Nacional de Antropología). Los antropólogos, al margen de monopolizar la cuestión indígena, lo que en un país como México no es poco, se convirtieron en los guardianes de la memoria, los sacerdotes encargados de mantener incólume el alma de la nación. Su simbiosis con el Estado fue doble, participaron tanto en el proyecto de modernización social como en la definición de lo que la nación mexicana era.

Esa dependencia y la imbricación de los antropólogos en el entramado político institucional de ese peculiar régimen autoritario que fue el mexicano nacido de la Revolución es un tema que merece, obviamente, mucho más espacio del que le puedo dedicar aquí ${ }^{50}$. El objetivo de este trabajo es mucho más

50 Sobre el indigenismo como antropología aplicada, en el caso mexicano, véase el sucinto 
modesto, mostrar cómo la nación fue representada en los tres grandes museos nacionales resultado de la primera gran reordenación museística posrevolucionaria, aunque el papel central que en ella tuvo y tiene el Museo Nacional de Antropología obliga a que se preste más atención a este que a los demás.

Las glorias del pasado prehispánico expuestas en la primera planta del museo sirven para confirmar la imagen de un mundo indígena que forma parte del pasado, de algo muerto. El presente de las colecciones etnográficas del segundo piso es un presente indefinido que incita a la mirada condescendiente sobre fósiles vivientes tan intemporales como las piedras talladas del primero. Al presentar juntos los restos arqueológicos con las muestras etnográficas, algo habitual por lo demás en la mayor parte de los museos de antropología americanos, se convierte a los indígenas en algo muerto, reliquias que hay que cuidar y proteger pero no parte viva de la nación. Tal como afirma Marta Dujovne, referido a los museos de antropología de América Latina pero en un texto que parece inspirado directamente en el Museo Nacional de Antropología de México

La mayoría de los museos de antropología se dividen en una exposición arqueológica que muestra las culturas precolombinas, y una sección etnográfica, donde se representan formas de vida actuales o del último siglo, de las comunidades indígenas. El cuando de estas formas de vida resulta bastante ambiguo, porque estas exhibiciones dan por sentado un tiempo suspendido, o bien la idea de cultura sin cambios: «son» así. El presente etnográfico como medio de exposición crea la imagen de que también fueron y serán así. Falta la profundidad histórica, la descripción de los procesos, las modificaciones y, sobre todo, la vinculación con la otra historia, la de los otros, la de la Conquista, o la Colonia, o el Estado nacional, que se entrecruza y condiciona esos procesos [...] en nuestras exhibiciones etnográficas los indígenas parecen $[\ldots]$ pueblos aislados y sin historia ${ }^{51}$.

Los indígenas son México pero, desde la perspectiva de las clases medias y altas, son también siempre los otros, representan la nación pero no son la nación; los blancos no son México pero, desde la perspectiva de esas mismas clases medias y altas, han sido y son quienes hacen la historia de México. Extraña paradoja al que el discurso museístico, al menos tal como se expresa en los tres grandes museos aquí analizados, ha dado su aval. Y es que el bucle melancólico de la raza y el esencialismo identitario es un buen material para fabricar mitos de una cierta belleza poética, otra cosa es su relación con el principio de realidad.

pero sugerente trabajo publicado por José Palacios Ramírez en Cuicuilco, la revista de la Escuela Nacional de Antropología e Historia (Ramírez, 2004). Sobre el indigenismo en México la bibliografía es prácticamente inabarcable, Dietz, 1995. Fevre, 1999. Marzal, 1993. Villoro, 1950 , etc.

51 Dujovne, 1990. 


\section{REFERENCIAS BIBLIOGRÁFICAS}

Anderson, Benedict, Imagened Communities. Reflections on the Origin and Spread of Nationalism, Londres, Verso, 1983.

Bernal, Ignacio, Historia de la Arqueología en México, México, Editoria Porrúa, 1979.

Brading, David, Mito y profecía en la historia de México, México, Editorial Vuelta, 1988.

Breuilly, John, Nationalism and the State, Manchester, Manchester University Press, 1985.

Clavijero, Francisco Javier, Historia Antigua de México, México, Porrúa, 1987.

Dietz, Gunther, Teoría y práctica del indigenismo. El caso del fomento de la alfarería en Michoacán (México), Quito, Abya-Yala, 1995.

Dujovne, Marta, «Museo y comunidad: los contenidos de la exhibición», Ramón Bonfill Castro y Nestor García Canclini (eds.), Memorias del simposio: Patrimonio, museo y participación social, México, Instituto Nacional de Antropología e Historia, 1990.

Fernández, Justino, «Catálogo de las Exposiciones de Arte de 1964», Suplemento del número 34 de los Anales del Instituto de Investigaciones Estéticas, México, UNAM, 1965.

Fernández, Miguel Ángel, Historia de los museos de México, México, Banamex, 1987.

Fevre, Henri, El indigenismo, México, Fondo de Cultura Económica, 1999.

Florescano, Enrique, «Prólogo a la primera edición», Julio Cesar Olivé Negrete (coord.), INAH una historia, México, Instituto Nacional de Antropología e Historia, 1995.

Florescano, Enrique, «La creación del Museo Nacional de Antropología», Enrique Florescano (comp.), El patrimonio Nacional de México, México, Fondo de Cultura Económica, 1997.

Foucault, Michel, Las palabras y las cosas: una arqueología de las ciencias humanas, Madrid, Siglo XXI, 2006.

Franco, María Teresa, «Prólogo a la segunda edición», Julio Cesar Olivé Negrete (coord.), INAH una historia, México, Instituto Nacional de Antropología e Historia, 1995.

Gamio, Manuel, Forjando patria, México, Porrúa, 1982.

Gellner, Ernest, Nations and nationalism, Oxford, Basil Blackwell Publishers, 1983.

Hroch, Miroslav, Social Preconditions of National Revival in Europe, Cambridge, Cambridge University Press, 1985. 
Illades, Carlos, Presencia española en la Revolución Mexicana (1910-1915), México, UNAM/Instituto Mora, 1995.

«Información general de las actividades del Instituto Nacional de Antropología e Historia durante el año 1964», Anales, XVII (México DF, 1964): 7-16.

Knight, Alan, Nationalism, Xenophobia and Revolution. The Place of Forigners Interest in México. 1910-1915, tesis de doctorado, Oxford, Universidad de Oxford, 1974.

Lempérière, Annick, «Los dos centenarios de la independencia mexicana (1910-1921): De la historia patria a la antropología cultural», Historia Mexicana, XLV/2 (México DF, 1995): 317-352.

L'Etoile, Benoît de, Le Goût des Autres. De l'Exposition coloniale aux Arts premiers, París, Flammarion, 2007.

Lozoya, Johanna, Las manos indigenas de la raza española. El mestizaje como argumento histórico, México, CONACULTA, 2010.

Marzal, Manuel M., Historia de la antropología indigenista: México y Perú, Barcelona, Anthropos, 1993.

Morales, Luis Gerardo, Orígenes de la museología mexicana. Fuentes para el estudio histórico del Museo Nacional. 1780-1940, México, Universidad Iberoamericana, 1994.

Morales, Luis Gerardo, «Museológicas. Problemas y vertientes de investigación en México», Relaciones, 111, vol. XXVIII (Zamora, Michoacán, 2007): 31-66.

Molina Enríquez, Andrés, Los grandes problemas nacionales [1909], y otros textos [1909-1919], México, Era, 1978.

Olivé Negrete, Julio Cesar (coord.), INAH una historia, México, Instituto Nacional de Antropología e Historia, 1995.

Palacios Ramírez, José, «El indigenismo como antropología aplicada, algunos apuntes a contrapunto», Cuicuilco, 31 (México DF, 2004): 137-155.

Pérez Vejo, Tomás, Nación, identidad nacional y otros mitos nacionalistas, Oviedo, Ediciones Nobel, 1999.

Pérez Vejo, Tomás, España en el debate público mexicano, 1836-1867. Aportaciones para una historia de la nación, México DF, El Colegio de México/Instituto Nacional de Antropología e Historia, 2008.

Pérez Vejo, Tomás, «La construcción de las naciones como problema historiográfico: el caso del mundo hispánico», Historia Mexicana, LIII/2 (México DF, 2003): 275-311.

Pérez Vejo, Tomás, «Debates sobre la lengua española en el siglo XIX mexicano», Ínsula, 762 (Madrid, 2010a): 11-15. 
Pérez Vejo, Tomás, Elegía criolla. Una reinterpretación de las guerras de independencia, México DF, Tusquets Editores, $2010 \mathrm{~b}$.

Pérez Vejo, Tomás, «Historia, política e ideología en la celebración del Centenario mexicano», Historia Mexicana, LX/1 (México DF, 2010c): 31-84.

Seton Watson, Hugh, Nations and States. An enquiry into the Origins of Nations and the Politics of Nationalism, Londres, Methuen, 1977.

Sierra, Justo, Evolución política del pueblo mexicano, México, UNAM, 1957.

Torre, Guadalupe de la, y otros, Historia de los museos de la Secretaría de Educación Pública, México, INAH, 1982.

Urteaga Castro-Pozo, Augusto, «Museos y Exposiciones», Julio Cesar Olivé Negrete (coord.), INAH una historia, INAH, 1995.

Vázquez Olvera, Carlos, El Museo Nacional de Historia en voz de sus directores, México, Instituto Nacional de Antropología e Historia, 1997.

Villoro, Luis, Los grandes momentos del indigenismo en México, México, El Colegio de México, 1950.

Weber, Max, El político y el científico, Madrid, Alianza Editorial, 1994.

Womack, John, Zapata y la revolución mexicana, México, Siglo XXI Editores, 1969.

Yankelevich, Pablo, «Nación y extranjería en el México revolucionario», Cuicuilco, vol. 11, núm. 31 (México DF, 2004): 105-136.

Zea, Leopoldo, El Occidente y la conciencia de México, México, Porrúa, 1953.

Fecha de recepción: 13 de septiembre de 2011.

Fecha de aceptación: 21 de diciembre de 2011.

\section{History, Anthropology and Art: three subjects, two memories, and only one true nation}

Analysis of the reorganization of museums carried out by the Mexican State between 1944, the year of the inauguration of the refounded National Museum of History, and 1964, when the Anthropological and Vicerroyal national museums were inaugurated. The "narrative of the nation» underlying those inaugurations is also analyzed.

KEY WORDS: Mexico; $20^{\text {th }}$ Century; nation; museums. 